\title{
Open Source Introducing Policy and Promotion of Regional Industries in Japan
}

\author{
Tetsuo Noda and Terutaka Tansho \\ Shimane University \\ 1060 Nishikawatsu-cho, Matsue-City, Shimane Pref. 690-8504, Japan \\ nodat@soc.shimane-u.ac.jp, tansho@riko.shimane-u.ac.jp
}

\begin{abstract}
The development style of open source has a possibility to create new business markets for Regional IT industries. Some local governments are trying to promote their regional IT industries by adopting an open source in their electronic government systems. In this paper, we analyze the data of open source application policy of the Japanese government and case studies of promotion policy of local industries by local governments; for example, Nagasaki Prefecture and Matsue City. And it aims to extract the issues in the open sources application policy of local governments and the promotion policy of regional industries in Japan.
\end{abstract}

\section{Introduction}

In Japan, it is public organizations, especially central government offices that have guided adoption of open source. The Ministry of Internal Affairs and Communications (MIAC) that aims at the spread of the e-municipality system, started to put Linux in the list as one of the choices of OS when the electronic government system was introduced in 2004. Before this, the Ministry of Economy Trade and Industry (METI) also reported "Survey on Usage of Open Software; A Guideline for its Introduction" in 2003. In this report, such matters were examined as using OSS including Linux positively as a choice, a guideline for examining the arrangement of its introduction, and a legal problem, etc. Thus, open source software promotion organization "OSS Center", as an affiliated association of METI, was established in 2006. The OSS center has been collecting and offering technological information in cooperation with domestic major IT vender enterprises.

As a result of the open source promotion plan that centers on these central government offices, in the IT-Solution market in Japan, the market of public organizations occupies an especially large percentage. The IT solution market using open source was 917 billion yen in fiscal year 2006 (8.8\% of the entire IT solution market). It expanded to 1.05 trillion yen in 2007; an increase of 10.5 points compared to the previous year (10.8\% of the entire IT solution market), and is expected to expand to 1.16 trillion yen, an increase of 14.5 points compared to the previous year in 2008 . And, the ratio of the usage by public organizations to the entire open source market was 254 billion yen (24.2\% in composition ratio) in fiscal year 2006, and 227 billion yen (24.8\%) in fiscal year 2007. In Japan the public organizations occupy a big specific gravity in open source market, and they have still been guiding the growth of the entire open source market. 
In addition, after 2006, the open source introduction policy in Japanese local governments has been advanced by "Open source software use infrastructure agenda" of the OSS Center. Though this is a policy of doing financial support by the OSS Center when regional municipalities introduce open source in their local electronic government systems, the support load and other expenses are not considered for later years. Therefore, some local governments have difficulties in continuing the maintenance of their systems when the financial supports break off. Moreover, the number of enterprises with technologies that can continuously support open source in provinces is small, and this is also a factor that the introduction policy doesn't continue in local governments. Consequentially, the market is only created for the major IT vender enterprises that were involved in the initial introductions to the local governments.

Thus the introduction and the spread of open source policy have been advanced around the central government offices and the major IT vender enterprises, as the policy has been concentrated on the adoption and introduction of open source. As the result, it led to the expansion of the IT-Solution market among the major IT vender enterprises. It somehow succeeded in protecting the IT-Solution market of domestic IT vender enterprises from the foreign IT enterprises (Table 1 and Table 2$)^{1}$. But development method $=$ Cathedral type of the top down has not been able to be changed.

Table 1. Major IT enterprises' share in IT solution market using open source (*domestic IT vender enterprises)

\begin{tabular}{l|l|l|l}
\hline & 2006 & 2007 & 2008 \\
\hline Fujitsu* & $7.3 \%$ & $8.6 \%$ & $9.3 \%$ \\
IBM & $7.2 \%$ & $7.1 \%$ & $6.9 \%$ \\
NEC* & $6.2 \%$ & $6.7 \%$ & $6.9 \%$ \\
HITACHI* & $5.0 \%$ & $5.3 \%$ & $5.9 \%$ \\
HP & $1.4 \%$ & $1.4 \%$ & $1.5 \%$ \\
Sun & $0.6 \%$ & $0.6 \%$ & $0.6 \%$ \\
\hline
\end{tabular}

Table 2. Major IT enterprises' share in IT solution market in the public organizations using open sources (*domestic IT vender enterprises)

\begin{tabular}{l|r|r|r}
\hline & 2006 & 2007 & 2008 \\
\hline Fujitsu* & $10.1 \%$ & $10.3 \%$ & $10.7 \%$ \\
NTT-Data* & $9.3 \%$ & $9.4 \%$ & $9.5 \%$ \\
NEC* & $8.3 \%$ & $9.3 \%$ & $9.8 \%$ \\
HITACHI* & $7.9 \%$ & $8.5 \%$ & $9.1 \%$ \\
IBM & $4.4 \%$ & $4.3 \%$ & $4.2 \%$ \\
\hline
\end{tabular}

On the other hand, the development style of open source is extending beyond the boundary of organizations, so it has the possibility to create new business markets for regional IT industries. So some local governments are trying to promote their regional IT industries by adopting open source in their electronic government systems. In the later sections, we analyze the data of open source application policy of Japanese government

${ }^{1}$ MIC Economic Research Institute (2008). 
and case studies of promotion policies of local industries by local governments, for example, Nagasaki Prefecture and Matsue City of Shimane Prefecture, located in a typical local country area in Japan.

\section{Introduction of OSS and Promotion of Regional Industries}

\subsection{The Method of Divided Orders by Using OSS in Nagasaki Prefecture}

Actually, in introducing OSS at the local government level, in addition to Introduction/Management-cost reduction of the IT system of the municipality, local industry promotion has been advanced in Japan. A typical case is the construction of "Electronic Prefectural Government System" in Nagasaki Prefecture.

Nagasaki Prefecture invited CIO from a private organization in 2001, and adopted open source system for the basic technology of the electronic Prefectural government systems which consist of three functions (document management, application and tenders). Then, the orders, that used to be placed as a whole with major IT vender enterprises in Tokyo, are now divided to small systems before ordering.

Why did it become possible? Because, (1) The staff in the prefecture made specifications of the systems, (2) When the external program development was consigned, the divided orders decreased the budget for a matter, (3) The technology was decided before system was constructed. These processes enabled local small and mediumsized IT enterprises in Nagasaki to participate in the development of these systems. By this method, expenditure related to the computer system of the prefecture was greatly reduced with 694 million yen in fiscal year 2003 from 991 million yen in fiscal year 2002. This cost continues for five years for the leasing contract of the server system. But, when the server systems consisting of a mainframe, are completely replaced by the Linux server in five years, Nagasaki Prefecture estimates that the entire cost will be compressed into $30 \%$ of that of 2002 (Figure 1$)^{2}$.

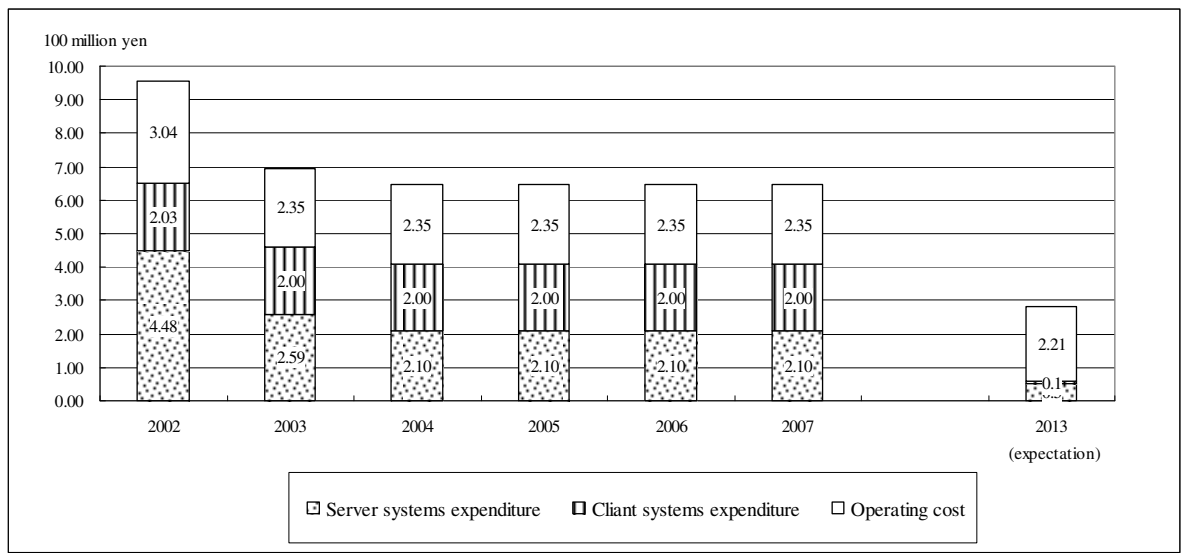

Fig. 1. Introduction/Management cost reduction of the IT system by using OSS in Nagasaki Prefecture

\footnotetext{
${ }^{2}$ Nagasaki Prefecture (2008).
} 
Moreover, it becomes possible also for the local IT enterprises to participate in the system development by the divided order method. As a result, they received 48/100 orders directly in 2002- 2003 fiscal year (15.1\% in terms of monetary amounts), and $73 / 96$ orders in 2004 fiscal year $(32.7 \%$ in terms of monetary amounts) (Table 3 ).

Table 3. Ratio of order receipt for local IT enterprises in the Nagasaki e-municipality system

\begin{tabular}{r|r|r}
\hline & Number of Cases & Amount of Money \\
\hline Before 2001 & No Result & No Result \\
2002 & $47.9 \%$ & $15.2 \%$ \\
2003 & $48.1 \%$ & $15.1 \%$ \\
2004 & $76.0 \%$ & $32.7 \%$ \\
2005 & $75.4 \%$ & $46.3 \%$ \\
2006 & $82.1 \%$ & $69.3 \%$ \\
2007 & $88.1 \%$ & $62.8 \%$ \\
\hline
\end{tabular}

Adopting the open source policy and divided orders made it possible for them to expand the market for the local IT enterprises. But, this would not last longer than several years because the entire cost of the electronic government systems in Nagasaki was compressed in 2003. However they have expanded the ratio of the market, although it is obvious that the total pie has been cut back. They have to develop new market of open source. Nagasaki Prefecture's regional-industry promotion plan needs to move on to the next stage.

\subsection{Opening of Source Codes and Regional-Industry Promotion}

In Nagasaki, by this method of divided orders, local IT enterprises were encouraged to participate in the processes of making specifications and entry into the processes of the project and decision making for specifications that had been major IT vender enterprises' "Role", so that they could not only increase their orders of "Electronic Prefectural Government System" but also improve their abilities in project management.

In 2004, Nagasaki Prefecture announced the plan to shift legacy system from mainframe to Linux within eight years. Moreover, the source codes of their three systems, "Vacation system", "System of WEB list of government officials" and "Document keeping system" were opened to the public in 2005. These systems had already been decided to be introduced also to other prefectures such as Tokushima Prefecture and Wakayama Prefecture. This shows the possibility of expanding the market for the IT enterprises in Nagasaki Prefecture (The orders from outside of Nagasaki Prefecture have also increased).

Thus, there has already been a success case of promotion of the local IT enterprises, by introducing OSS, and to expand Market in Japan. In the system construction of a local government, it not only adopts OSS which local IT industries have developed, as a user $=$ a purchaser, but also, if products are open to the public on Internet as OSS, it can promote many chances that the local IT industries can expand their own market on a nationwide scale. "Cathedral type development method" or "Vender lock-in" by major 
IT vender enterprises can be released, so the local IT industries can participate in the process of software development and receive orders of the systems that have been divided in small sizes.

However, to make this process possible, as was shown in the case in Nagasaki Prefecture, the staff of the administration sector must participate in the upper processes of the software development, such as processes of "Requirement definition" or "Design". The reason why major IT vender enterprises secured orders of their own was that they had participated in these processes. Nagasaki Prefecture's case was, so to speak, an indirect development aid by the administration whose staff in the prefecture were related to these processes of "Requirement definition" and "Design", so it enabled them to achieve regional-industrial promotion plan.

Moreover, if they only aim to lock up the market of any local electronic government systems, they will come up against the cutting back of these total markets, and the scramble for the market would result. As is shown in Table 3, the local IT enterprises' order ratio in amount of money had increased till 2006. But it decreased by 6.5 points from 2006 to 2007. This is because that the other local IT enterprises out of Nagasaki invaded the market of the electronic Prefectural government systems in Nagasaki. The scramble for the open source market had already started. This may be the fact, but there will be another method for the regional-industry promotion plan.

\section{OSS Development Style and Regional-Industry Promotion}

\subsection{Situation of Regional IT Industries in Shimane Prefecture}

As we have mentioned above, in introducing OSS to local governments, their staff need to participate in the upper processes of the software development. And, the staff in Nagasaki Prefecture exactly did it. The reason why Nagasaki Prefecture decided to start this regional-industry promotion project is that most of the regional IT industries in Japan depend on their regional public organizations' orders for their market. And it is obvious that the market will reduce in later years because of the critical financial situation in Japan.

The situation is also the same for Shimane Prefecture. As is shown in Figure 2, their main market for IT enterprises is "Information Service Industries" themselves, amounting to $37 \%^{3}$. It is so high a ratio compared to that of the whole of the country $(28.3 \%)^{4}$. It shows the multiple chains of commission and entrust among the same trade relations in Japanese IT industry, which is a typical water fall model of development. The local IT enterprises depend on the major IT vender enterprises in Tokyo for their receiving of orders.

And "Administration Sector" (22\%) and "Construction Industry" (9\%) follow in the commercial report of Shimane. In the national report those ratios are $8.6 \%$ and $1 \%$, respectively. On the other hand, "Service Industry" (16\%) and "Finance and Insurance" (1\%) are extremely low compared to the whole in the country. It is shown that the orders are given by major enterprises outside Prefecture.

\footnotetext{
${ }^{3}$ Shimane Prefecture (2005).

${ }^{4}$ The Ministry of Economy Trade and Industry of Japan (2005-2008).
} 

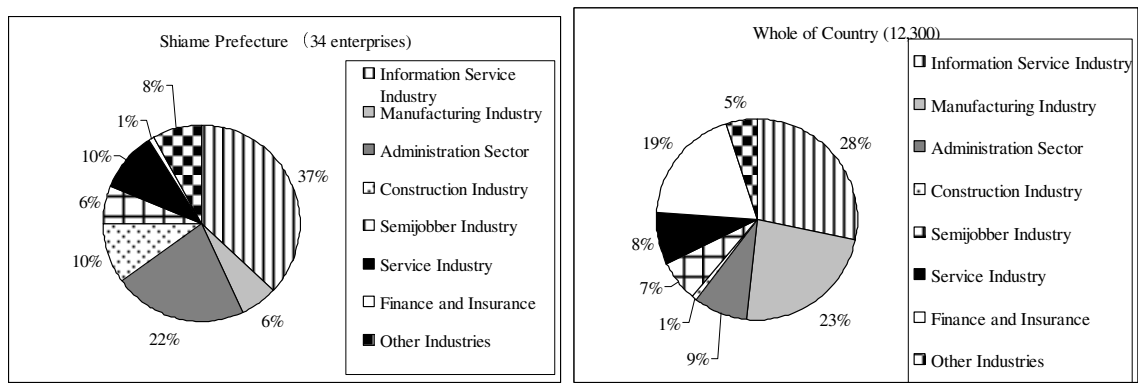

Fig. 2. The receipt of orders for IT industries from different industry categories in Shimane and Japan (Whole of country)

The orders from "Administration Sector" and "Construction Industry" had already been decreasing in nationwide scale. If they had depended mainly on the orders in these fields indefinitely, the sales would have clearly declined fast. Shimane Prefecture faced the need to make a choice whether waiting for the reduction of the market or starting regional industry promotion policy.

Additionally, when we asked what skills were mostly insufficient in these enterprises, the first listed answer was not the ability of "System Development"(26\%) but the ability of "Project Management"(65\%) which is dominated by major IT vender enterprises in Tokyo, and the local IT enterprises in Nagasaki acquired it by participating in the electronic Prefectural government systems (Figure 3).

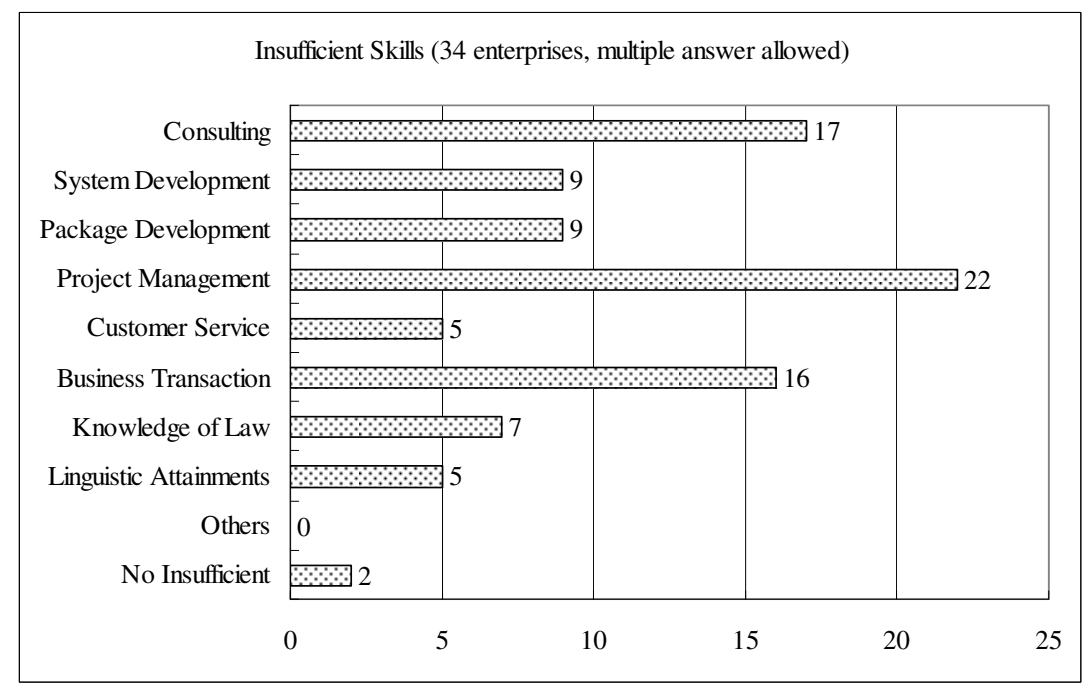

Fig. 3. Insufficient Skills of the IT enterprises in Shimane Prefecture 


\subsection{OSS Ruby and Ruby City Matsue Project in Shimane Prefecture}

Matsue City is the capital city of Shimane Prefecture. In the city, 70\% of IT enterprises and workers of the Prefecture are concentrated. And it was necessary to change this trend, because of the reduction of the market for the local IT enterprises. So, Matsue City and Shimane Prefecture began to learn from the case of Nagasaki Prefecture, but they thought it was difficult to instruct city's administration staff to acquire the skill to participate in the upper processes of the software development in a short term. They calculated the cost for the labor improvement and the specificationdecision ability of administration staff, including invitation of CIO. Consequently they came to the conclusion that adopting open source for the electronic municipality systems could not necessarily cut the budget of the administration totally.

At the same time, Matsue City, having their own regional open source resource "Ruby", intended to make open source development style in the industrial promotion plan. The City adopted another method, a little different one from Nagasaki Prefecture's. It is not the style that the administration adopt open source for its electronic municipality systems but the style of promoting open source innovation.

Ruby is the Object-oriented Script Language invented by Mr. Yukihiro Matsumoto called "Matz" in the community, and opened to the public in 1993. Matz lives in Matsue City and has been developing Ruby with many developers all over the world through the Internet. At first, Ruby did not spread in business uses except among some fanatic engineers. But in 2004, David Heinemeier Hansson, a programmer in Denmark, released "Ruby on Rails" which is a web application framework. Hence, Ruby came to attract attention and to be used also in enterprise areas. Then Matsue City started the project, which attempts to create a new regional city based brand around the Ruby programming language, as part of its efforts to regenerate the City and its environs.

There has never been a regional-industrial promotion policy of using programming language that can be said "Statelessness". And, Ruby is the open source software developed and supported by the communities which consist not of a specific enterprise but of worldwide developers. Matsue City regarded this "Open" and "Statelessness" as a regional resource of the City, and tried to promote regional IT industry. To put it the other way around, Matsue City tried to start industrial promotion, which would be impossible by the City itself alone, by the support of worldwide community, like the development style of open source.

This project was named "Ruby City Matsue Project" and started in 2006. The project aims, through the "Matsue Open source Lab" facility, at creating a hub for all activities relating to open source software and making Matsue a centre for OSS research, development and exchanges. But, only by this project alone, it was impossible to improve the abilities of the project management which is the most insufficient skill in the local IT enterprises. The development power of Ruby would have been used only for major IT vender enterprises in Tokyo.

\subsection{OSS Development Style and Promotion of Regional Industries}

To support and advance this project, the organization of open source, "Open source Society Shimane" was also established in 2006, by enterprises, technicians, researchers, 
students, and users who specialize in open source software for them to be able to exchange knowledge and information, and to improve their technological development and project management abilities through utilizing "Matsue Open source Lab". Through such activities Matsue City will be able to become a national centre for open source software development, duly leading to new technological innovation, increased competitiveness in the field of OSS, and above all else the development of a modern workforce well versed in the intricacies of the IT world. Ultimately, it is expected to make Matsue City a world-renowned Mecca for Ruby and OSS.

In order to materialize its mission of promoting the local IT enterprises through open source initiatives, Open source Society Shimane conducts many varieties of activities in both fields of policy and technology. One of the Society's main activities is to hold "Open source Salon" in Matsue Open source Lab. This "Salon" is a series of study meeting or seminar in highly casual forms. The theme of the salon also varies; with government officials explaining their policy initiatives, university professors presenting the recent OSS or IT-related research results, and the Ruby or OSS engineers illustrating the cutting-edge OSS technologies, know-how and applications.

The salon has been held almost once a month for four years. With the number of audiences amounting to approximately 30 to 40, this salon becomes the "hub" for connecting people and information. With regard to the business area, the Society conducts "Business Exchange Meeting" when receiving the visitors from ICT-related enterprises outside of Shimane. This business meeting is exclusively for the members. Hence, the Society plays the hub role connecting people, information, technology, and businesses.

These are, so to speak, the Superficial Result, but most important purpose is industrial promotion by creating abilities in project management in the local IT enterprises. In Nagasaki Prefecture, the administration sector of the prefecture did it. On the other hand, in Matsue City "Open source Society Shimane", the organization of industrygovernment-academia complex in the region has been doing this role. By improving the abilities in project management, the local IT enterprises have been increasing the chances to participate in the upper processes of the software development. For example, "Medical and Nursery Care System of Matsue City" was constructed by "Techno Project" using Ruby in 2007, "Matsue SNS -Collaboration Effect of Regional SNS Connection" was opened by "Wacom IT" using Ruby on Rails in 2008, and "Knowledge Management System of Matsue City" by "NaCl" was constructed also using RoR in 2008. These are all local IT enterprises in Matsue City. Moreover, Shimane Prefecture developed "Shimane Prefecture CMS" using RoR to construct its own Web Site, and opened the source of "Shimane Prefecture CMS" to the public in 2008. Then, many other local governments come to get interested in this CMS and prepare to adopt it for their Web site. "Shimane Prefecture CMS" is, of course, open source, but to construct and maintain Web sites, the roles of private businesses are needed, and the orders mostly come to the local IT enterprises in Matsue City. As a result, according to the investigation report book by Shimane Prefecture Information Industry Association ${ }^{5}$, sales and the number of starting works of the IT enterprises in Shimane Prefecture show the expansion more than the whole country in fiscal year 2008 since fiscal year 2006.

\footnotetext{
${ }^{5}$ Shimane Prefecture Information Industry Association (2009).
} 
Table 4. Transition of Amount of Sales in IT industries (million yen)

\begin{tabular}{r|r|r|r|r}
\hline & Whole of Country & rate of increase & Shimane Prefecture & rate of increase \\
\hline 2006 & $13,751,730$ & & 10,452 & \\
2007 & $13,409,700$ & $-2.5 \%$ & 12,060 & $15.4 \%$ \\
2008 & $14,817,900$ & $10.5 \%$ & 13,241 & $9.8 \%$ \\
\hline
\end{tabular}

Table 5. Transition of Number of Persons Engaged in IT industries (man)

\begin{tabular}{r|r|r|r|r}
\hline & Whole of Country & rate of increase & Shimane Prefecture & rate of increase \\
\hline 2006 & 567,498 & & 1,022 & \\
2007 & 501,807 & $-11.6 \%$ & 1,389 & $35.9 \%$ \\
2008 & 557,263 & $11.1 \%$ & 1,537 & $10.7 \%$ \\
\hline
\end{tabular}

One of the key success factors of the project of Matsue City and Shimane Prefecture is the development power jointly collaborated with the nationwide open source community. By touching upon the nation wide expertise of the open source, Matsue City and the project-related people have recognized the crucial importance to cooperate with the open source of the whole country which connects further to the worldwide open source community. In addition, a personnel training and industrial promotion are advanced by the cooperation of the industry-government-academia complex in the region. In Nagasaki Prefecture, the prefecture itself participated in the upper processes of the software development and divided their own orders to local IT enterprises. On the other hand, in Matsue City, local IT enterprises in the city gather and collaborate through "Open source Society Shimane", the industry-governmentacademia complex as a catalyst, and improve their abilities of project management to acquire the orders and expand Markets. In both cases, adoption of the development style of open source can make the possibilities to expand more Markets outside of the regions 3 OSS Development style and Regional-Industry Promotion.

\section{Conclusions}

In the development style of open source, so to speak "Bazaar Style Development", a lot of researchers, developers, and also enterprises voluntarily participate in the organization, extending the boundary of the organizations. So it has the possibility to create new business markets to regional IT industries. But, the open source application policy or the adoption assistance to local governments requires the capabilities in technique, development, and project management, both for adoption sides and provider sides. As the result, it tends to lead to the expansion of the IT-Solution market among the major IT vendor enterprises.

However, as was shown in the case in Nagasaki Prefecture, once the staff of the administration sector (the adoption side) participates in the upper processes of the software development, they can get the ability in project management and divide the orders of their own to be placed. This process enables them to expand the market for the local IT enterprises. And, acquiring the orders by participating in developing 
processes, they can improve the abilities in technologies corresponding to the development of open source including the project management and decision making for specifications. Moreover, if the deliverables are opened, the market will expand much further for the IT enterprises in Nagasaki Prefecture. This is the indirect development aid by the administration to promote the regional IT industry.

On the other hand, as typically shown in the "Ruby City Matsue Project", there is another method to develop the ability of the provider side. In local cities in Japan, enterprises tend to depend on the orders from "Administration Sector" of their areas. It is obvious that these orders would not last for a long time in the future. Matsue City and Shimane Prefecture took the choice of this method, which not only uses open source technology but also adopts open source development style.

Thus, local governments in Japan can somehow lead regional-IT industry promotion policies, but the main constituents are local government administrations. Because that the local IT enterprises themselves have little motivation for improving their technological abilities which can expand their market. This is the one problematic point. And, the more acute point is that if they come up against the scramble for the market they wouldn't have the ability to overcome by themselves.

I think, while the competition between regions may accompany it, cooperation and collaboration of regions are also needed to expand their market, and to compete against the major IT vender enterprises. Though this may be a matter of the policy and the business, it is necessary to gaze at it as a research object.

\section{References}

1. MIC Economic Research Institute: Current State and View of OSS Using IT Solution Market in Japan (2008)

2. The Ministry of Economy Trade and Industry of Japan: Specific Service Industry Investigation of Actual Conditions (2005-2008)

3. Nagasaki Prefecture: Promotion of Computerization from Purchaser Subject (2008)

4. Shimane Prefecture: Shimane Prefecture Commerce and Industry Labor Division (2005)

5. Shimane Prefecture Information Industry Association: Investigation Report Book of Software Industry in Shimane (2009) 